\title{
Research on Information Maintenance and Management System of Bridge Group over Wei-River
}

\author{
Liangliang Zhai ${ }^{1, a}$ \\ ${ }^{1}$ College of Science, Xi'an Shiyou University, Xi'an, Shaanxi Province, 710065, P.R. China \\ a abcwbs8866@163.com
}

\begin{abstract}
Key words: bridge management system; bridge group; standardization; variable weight evaluation Abstract. After analysing the advantages and disadvantages of the existing bridge management system, method about the establishment of optimized bridge maintenance and management system have been put forward. Analysed from three aspects including business process, disease gallery and standardization of data collection, effective measures were explored to guarantee the accuracy of initial data input to the maintenance system. Based on the hierarchical system of single bridge in the existing standard, the introduction of the concept of bridge group was introduced to build a management system of bridge structure group. An improved method to evaluate the technical condition of bridge structure was proposed and related software platform was built, as a result, the information maintenance and management system to synthetically control the bridge group in Shaanxi Weihe has been established.
\end{abstract}

\section{Introduction}

Bridge management system BMS is an important means to replace the original method through handwritten notes to record the bridge technology level and assist the bridge maintenance and management department to achieve bridge electronic data entry. The system is able to effectively manage the bridge structure information, disease data, technology level and bridge maintenance information, which is convenient for users to retrieval from massive data.

\section{Current Research Situation of Bridge Management System}

Current Research Situation in Foreign Countries. The first Bridge Management System BMS is the National bridge file database NBI (national bridge inventory) established by the Federal Highway Administration. In 1968, the Federal Highway Administration set up a "national bridge inspection group" who established the prototype of bridge maintenance management system-National bridge NBI to achive the nation's bridge data. The primary data file has only preliminary data management and auxiliary functions.

In 1989 the Federal Highway Administration researched and developed Ponti. The software was authorized by the American Association of state highway and transportation officials (AASHTO) for the use of 45 state departments of transportation and other agencies. In1990, Pontis was improved through NCHRP project funded Federal Highway Administration (FHWA) to develop BrM[1], the bridge maintenance software with the largest influence to the United States. BrM was soon handed over to the American Association of state highway and transportation (AASHTO) for further development. By using the new method of AASHTO about bridge components division, inspection and evaluation, BrM was widely used in the United States and international transportation agencies.

Compared with the United States, Europe bridge management system was started late but developed rapidly. The Danish DANBRO system, NATs systems in the UK and Norway Brutus system are distinctive [2,3]. Scanprint of France [4] is one of the outstanding representatives, which has been applied to the gamma bridge of Portugal, Rion-Antirion Bridge of Greek [5] and Confederation Bridge of Canadian [4]. The Nanjing Yangtze River Bridge [5] and Zhoushan Island Bridge [6] also used the Chinese version of Scanprint. 
In Asia, Japan developed the bridge management system JH-BMS[7] which was consistent with their own maintenance system. JH-BMS bases on the foundation of bridge management system in the United States.

Current Research Situation in China. The development of bridge maintenance management system in China is relatively late, and the bridge maintenance management system is developed in the late 80's. At present, the CBMS (China highway bridge management system) is the most representative in China, which was developed by the Research Institute of the Ministry of Transportation in 1993 [8]. The analysis results provide reliable data for the user to ensure optimal allocation of network capital, and combined with the latest version of GIS (Geographic Information System) technology, makes the system more abundant. CBMS laid a solid foundation for the development of China's bridge management system. Based on the experience of foreign in the development, according to the specific conditions in China, the highway management unit in Sichuan, Guangdong, Beijing and other places has developed bridge database system of Sichuan Province, bridge maintenance and management system of Guangdong Province, Beijing bridge maintenance and management system, etc. [9].

Assessment of Current Situation. The research of bridge maintenance and management system indicates that the existing system mainly has the following two problems: (1) The uncertainty of data collection is large. When running the existing bridge maintenance and management system, the data was collected mainly through the inspection personnel handwritten notes and then input to the main web system. In the process of data collection, the existing system can't provide standardized disease Gallery to detect personnel, and grade of bridge disease was judged mainly through the detection personnel subjectively, so the bridge condition assessment may be impacted by the knowledge level of the bridge inspection personnel, cognitive ability, professional ethics and mental state. (2)The bridge evaluation method system is not perfect.The theoretical basis of the development of bridge maintenance management system is our country code of bridge maintenance, while in 2011, China issued a new implementation <JTG/T H21-2011[S] Standard for technical condition assessment of Highway Bridges $>[10]$. At present, a large parts of the bridge management system in China have not written the new evaluation method into, which reduced the reliability of bridge technical condition evaluation.

\section{Background Works}

$<$ Planning and implementation project along Weihe River in Shaanxi Province>[11] plans to construct the riverside drive along the Weihe River which is 475.6km long in "Twelfth Five Year Plan" period. By the project, 55 traffic bridges flowing into the Wei River were built, with different structural styles and spans.

The traffic bridges along Weihe River should endure grave test from floods, overloading of vehicles, natural environment (wind, temperature, the harmful components in the atmosphere) and earthquake in recent 100 years. The research on the system of comprehensive management of the Weihe River Bridge Group is the inevitable requirement about the 55 bridges' safety security, scientific management and integration of the resources.

\section{Development of Information Maintenance and Management System about Bridge Group}

The Standardization of the Maintenance and Management System. (1) Standardization of business processes. According to the < maintenance specification of bridge on highway > (JTG H11 2004[S]) [12] inspection and maintenance works were divided meticulously to distinct the responsibilities of maintenance personnel with different levels. According to the < China Bridge Management System V12 cataloguing code set > of Road Research Institute in transport department, the codes were edited to establish the data dictionary, and then the maintenance and operation were standardized.

(2) Standardization of disease gallery. After researching on a large number of bridge diseases (especially pay attention to the disease characteristics of bridge about water conservancy engineering), 
the standard library was established referencing the <Bridge inspections pocket coding Guide $>$ written by Oregon Department of transportation and <Pontis bridge inspections Manual> compiled by Michigan Transportation Department. Library of standard disease of bridge descripts the quality and quantity of every disease with intuitive pictures. The disease library also provides the causes leading to disease, preventive measures and countermeasures of maintenance.

(3) Standardization of data collection. The data can be collected by Android mobile terminal or inspection terminal of windows tablet. The function of the Android mobile inspection terminal was only limited to inspection of electronic records instead of paper records with standard disease gallery for inspection personnel to analysis on the spot in order to ensure the accuracy of inspection results. Compared with Andriod mobile terminal, the function of windows tablet version also include editing bridge structure static information (including solution analysis of the structure), viewing the structure of the 3D model, engineering drawings, inspection drawings and other multimedia information, and technical condition evaluation, excepting the site inspection of electronic records.

Combined Management of Bridge Group and a Single Bridge Structure. Current < assessment standard of highway bridge condition > (JTG / H21 - 2011) [10] divides bridge for four layer system, namely bridge $>$ site $>$ members $>$ component, but 4 layer classification system applies to single bridge. In order to make the management and safety evaluation of bridge group and single bridge structure combined in a system, the concept of sub component, component assembly, the unit score, bridge and bridge group is introduced to build bridge group structure management system.

A plurality of bridge group automatic format group of bridge, and bridge group is made up of several bridges, while a bridge can also belong to different bridge groups at the same time. Users can easily and quickly find one or more bridges needed to examine from large database.

Method of Variable Weight Comprehensive Evaluation. The constant weight and hierarchy analytic procedure is used in existing specification for bridge condition assessment. But the evaluation results of this method can't reflect the true bridge technical condition level when the bridge member distributed little weight produces serious disease. Therefore, variable weight theory was introduced in based on the hierarchical evaluation to improve the authenticity of the evaluation results.

The comprehensive evaluation method with variable weight and the existing standard evaluation method combine to a new evaluation method system: including the two assessment methods with constant weight of the existing norms and variable weight comprehensive evaluation method can be defined by the users. In order to adapt to the variable weight theory, the system provides 2 kinds of methods to adjust weight for the user:

(1) Direct modification of the weights of the components. The method allows the user to of the components regulated in < maintenance specification of highway bridge > (JTG H11 - 2004[S]) [12]. Users can redistribute the weights according to the engineering experiences or the specific circumstances of bridge to increase in the weights of the key positions and the components, and then obtain the bridge technology level more in line with the actual situation.

(2) Setting variable weight coefficient with the level of part or component. The method allows the user to set the variable weight coefficient for the whole bridge or the bridge site, and the system automatically redistributes the weight for the bridge to avoid the possibility error caused by the inappropriate input of users.

Software Development. The system is based on B/S structure (Browser/Server, browser / server). Compared to the other way, the development model makes the development, maintenance and use of system simplifying. The client only needs to install the browser to exchange data with the host database through the Web service. The development of system database uses SQL Server. Compared with other bridge maintenance and management system, the database of system above also contains the foundation data table of bridge, regular check table and periodical check table and so on, what's more, the current system increased the bridge site data table, data structure of bridge group table and bridge group data table, in order to achieve the comprehensive management of the 55 bridges. 


\section{Conclusions}

According to the method of this paper, standardization of initial input information to the bridge maintenance management system has implemented and the bridge group structure management system has been established. The comprehensive management and maintenance platform using variable weight comprehensive evaluation method can effectively solve the daily management and maintenance problems of the 55 bridges over Weihe Rive, which significantly improving the information level of bridge maintenance and management.

\section{Acknowledgements}

The work described in this paper was partially supported by Fok Ying Tung Education Foundation (Grant No. 141278).

\section{References}

[1] Aashto. The aashtoware ${ }^{\mathrm{TM}}$ bridge management software BrM[Z]. 2014.

[2] Tan Jinhua, Lv Xiujie, Xu Jun, et al. Overview of European bridge management [J]. world bridge. 2004, (3): 52-55.

[3] Wang Yongdao, Chen Zhen, He Zhongyou, et al. A brief introduction of the Danish bridge management system [J]. Guangdong highway traffic. 1994, (3): 48-61.

[4] Stubler J, Bis E L, Diouron T L. Scanprint ${ }^{\circledR}$ : inspection and maintenance computer program for structures[J]. Transactions, Smirt. 2001, (16): 1451-1457.

[5] Hovhanessian G. Health monitoring of cable-stayed structures experience and implementation[A]. Proceedings of IMACXXIV[C]. St. Louis USA.

[6] Shen Wang, Zhang Qiang. The maintenance and management system of bridge electronic artificial patrol [J]. China Engineering Science. 2010, 2 (7): 57-60.

[7] Miyamoto A. Development of a Bridge Management System (J-BMS) in Japan[J]. Life Cycle Cost Analysis and Design of Civil Infrastructure Systems. 2001: 179-222.

[8] Beijing New Technology Development Co. Ltd. China highway bridge management system V12 user manual [R]. Beijing, 2012

[9] Wang Xiaojing, Liu Yong. Su Tong Bridge Management System [J]. highway traffic technology (Application Technology Edition). 2010, (4): 5-8.

[10] Department of transportation and Highway Science Research Institute. H21-2011 JTG/T highway and Bridge technical condition assessment standard [S]. Beijing, 2011

[11] Weihe Province, Shaanxi Province, across the board planning and implementation of the program. The Shaanxi Provincial Water Resources Department 2011.1. [R].

[12]The people's Republic of China industry standard. JTG H11-2004 specification for maintenance of highway bridges and culverts [S]. Beijing, 2004 